\title{
Predictive value of ventricular arrhythmias for patency of the infarct-related coronary artery after thrombolytic therapy
}

\author{
Department of \\ Cardiology, \\ St Antonius Hospital, \\ Nieuwegein, \\ The Netherlands \\ A J Six \\ $\mathrm{J} H$ Kingma \\ N M van Hemel \\ Department of \\ Cardiology, Medisch \\ Spectrum Twente, \\ Enschede, \\ The Netherlands \\ J H Louwerenburg \\ Department of \\ Cardiology, \\ University Hospital, \\ Utrecht, \\ The Netherlands \\ E O Robles de Medina \\ Correspondence to \\ Dr A Jacob Six, \\ GH Besselaar Associates SA, \\ Avenue de Tervueren 273 \\ Avenue de Tervueren
Bte 3, 1150 Brussels, \\ Belgium. \\ Accepted for publication \\ 24 April 1991
}

A Jacob Six, J Hans Louwerenburg, J Herre Kingma, Etienne O Robles de Medina, Norbert $M$ van Hemel

\section{Abstract}

In animal studies reperfusion of coronary arteries is commonly accompanied by ventricular arrhythmias. It is not certain, however, whether ventricular arrhythmias can be used as a reliable non-invasive marker of reperfusion in humans. Two-channel Holter recordings were obtained from the start of an intravenous infusion of streptokinase until coronary angiography $(2 \cdot 8 \quad(2 \cdot 7)$ hours (mean (SD)) afterwards) in 57 patients with acute myocardial infarction of less than four hours who were generally not treated with antiarrhythmic drugs. Ventricular arrhythmias occurred in $21(37 \%)$ of the 57 patients: accelerated idioventricular rhythm in 13 patients and non-sustained ventricular tachycardia in 15 patients. Seven patients had both accelerated idioventricular rhythm and nonsustained ventricular tachycardia. Coronary angiography showed a patent infarct-related vessel in $12(92 \%)$ of the 13 patients with accelerated idioventricular rhythm (95\% confidence interval 66 to $99 \%)$, in $22(50 \%)$ of the 44 patients without accelerated idioventricular rhythm (95\% CI 34 to $66 \%)$, in $11(73 \%)$ of the 15 patients with nonsustained ventricular tachycardia (95\% CI 45 to $92 \%)$, and in $23(55 \%)(95 \%$ CI 39 to $71 \%$ ) of the 42 patients who did not have non-sustained ventricular tachycardia. Seventeen $(81 \%)$ of the 21 patients with accelerated idioventricular rhythm, or non-sustained ventricular tachycardia, or both, had a patent infarct-related vessel (95\% CI 58 to $94 \%$ ) as did $17(47 \%)$ of the 36 patients with no ventricular arrhythmia (95\% CI 29 to $65 \%$ ).

In patients with accelerated idioventricular rhythm after thrombolysis the infarct-related vessel is almost certain to be patent; but the infarct-related coronary artery can still be patent when no arrhythmia is seen.

Because intravenous thrombolytic agents are increasingly used to treat acute myocardial infarction non-invasively determined indices of reperfusion are needed. ${ }^{1}$ Ventricular arrhythmias are regarded as a reliable sign of reperfusion in most, but not all, laboratory animals. ${ }^{2-6}$ In humans, however, some of the arrhythmias seen in the first hours after the onset of infarction can be attributed to the inherent electrical instability of the ischaemic myocardium and not to reperfusion. To investigate the difference between "infarction arrhythmias" and "reperfusion arrhythmias", we need to measure the patency rate of the infarct-related coronary artery and disorders of the heart rhythm within a well-defined interval.

We therefore determined the predictive value of ventricular arrhythmias for patency of the infarct-related vessel in patients with acute transmural infarction by monitoring the heart rhythm with Holter recording from the start of streptokinase administration until angiographic visualisation of the infarctrelated vessel up to four hours later (that is, the study period).

\section{Patients and methods}

PATIENTS

Fifty seven patients with acute myocardial infarction were treated with intravenous streptokinase. We studied male and female patients below the age of 71 years with symptoms of acute myocardial infarction for less than four hours and ST segment elevation of $\geqslant 1 \mathrm{~mm}$ in at least two leads of the standard 12 lead electrocardiogram. We excluded patients with a history of abnormal bleeding, use of anticoagulant drugs, recent surgery ( $<2$ weeks), previous cerebral haemorrhage or injury, impaired renal function (serum creatinine concentration $>300 \mu \mathrm{mol} / \mathrm{l}$ ), systolic blood pressure $>200 \mathrm{~mm} \mathrm{Hg}$, diastolic >120 mm Hg, severe heart failure with pulmonary congestion on admission, any malignancy (except those of the skin), or previous treatment with streptokinase.

All patients were informed of the treatment and its potential risks and were asked for consent. $\beta$ Blockers were used on the day before or on the day of admission by 10 patients and calcium antagonists by six patients. During the study period 10 patients were treated with atropine for bradycardia or atrioventricular conduction disturbances. Lignocaine was given to five patients, in two by continuous infusion after an episode of ventricular fibrillation before admission to the coronary care unit. In the three other patients lignocaine was given as a bolus injection at home by the general practitioner for unknown reasons, probably extrasystoles.

\section{TREATMENT}

Twenty patients were treated as part of a 
dose-ranging trial of streptokinase ${ }^{7}$ in which they received a one hour infusion of 200000 IU $(\mathrm{n}=4), \quad 750000$ IU $\quad(\mathrm{n}=6)$, $1500000 \mathrm{IU} \quad(\mathrm{n}=5)$, or $3000000 \mathrm{IU}$ $(\mathrm{n}=5)$ of streptokinase (Kabikinase). Twenty four other patients were treated with $1500000 \mathrm{IU}$ of intravenous streptokinase plus oral or intravenous captopril (Capoten) in an attempt to diminish reperfusion damage of the myocardium, as described elsewhere. ${ }^{8}$ Thirteen other patients were given 1500000 IU of intravenous streptokinase only. The infusion was stopped if allergic reactions, bleeding complications, or a fall in blood pressure developed. Steroids, antiarrhythmic drugs, or salicylates were not used routinely. Analgesic drugs and nitrates were given freely. Coronary angiography was performed within four hours of the streptokinase infusion.

\section{CORONARY ANGIOGRAPHY}

Coronary cineangiography was performed by the Judkins approach. Immediately after the introduction of a sheath in the femoral artery, patients were given $5000 \mathrm{IU}$ of heparin. Furthermore, each patient was treated with $2.5 \mathrm{mg}$ isosorbide dinitrate sublingually. The right coronary artery was usually filmed in two projections and the left coronary artery in at least three views. All coronary angiograms were independently analysed by cardiologists who specialised in coronary angiography. The perfusion of the infarct-related vessel was classified according to the thrombolysis in myocardial infarction (TIMI) study group": patency was defined as TIMI perfusion class II or III.

\section{HOLTER RECORDINGS}

A two-channel Holter recorder was connected to the patient immediately on admission. Soon after infusion of streptokinase began. Recording continued until angiography of the infarct-related vessel was completed. All recordings were manually analysed on a beatto-beat basis (paper speed $25 \mathrm{~mm} / \mathrm{s}$ ) by one experienced cardiologist (JHL) and all arrhythmias detected were recorded on paper.

\section{DEFINITIONS OF ARRHYTHMIAS}

Accelerated idioventricular rhythm was defined as the occurrence of at least three consecutive uniform complexes of ventricular origin with a frequency of 60 to 100 beats/ minute. Non-sustained ventricular tachy- cardia was defined as at least three consecutive ventricular complexes with a frequency of more than 100 beats/minute, for $<30$ seconds. Sustained ventricular tachycardia was defined as a ventricular tachycardia lasting 30 seconds or more.

\section{STATISTICAL ANALYSIS}

Continuous distributed values are given as the mean (SD). Sensitivity was defined as the percentage of patients with an open vessel with the rhythm disturbance under examination; specificity was defined as the percentage of patients with an occluded vessel who did not have that rhythm disturbance. The results are given with $95 \%$ confidence intervals. ${ }^{10}$

\section{Results}

Table 1 shows the characteristics of patients with various rhythm disturbances. Ventricular arrhythmias occurred in $37 \%(21 / 57)$ of the patients: accelerated idioventricular rhythm in 13 patients and non-sustained ventricular tachycardia in 15 patients. Both accelerated idioventricular rhythm and non-sustained ventricular tachycardia occurred in seven patients. Sustained ventricular tachycardia and ventricular fibrillation were never recorded.

Patency of the infarct-related vessel was seen in $92 \%(12 / 13)$ of patients with accelerated idioventricular rhythm and $50 \%(22 / 44)$ of those without; and in $73 \%(11 / 15)$ of the patients with non-sustained ventricular tachycardia and 55\% (23/42) of those without ventricular tachycardia. The infarct-related vessel was patent in $81 \%(17 / 21)$ of the patients with accelerated idioventricular rhythm or non-sustained ventricular tachycardia or both. Forty seven per cent $(17 / 36)$ of patients without ventricular arrhythmia had patent vessels. Six of the seven $(86 \%)$ patients who had both accelerated idioventricular rhythm and nonsustained ventricular tachycardia had patent vessels.

Both patients who had an episode of ventricular fibrillation before admission to the hospital had patent infarct-related coronary arteries as did $70 \%(7 / 10)$ of patients who were treated with atropine for bradycardia. In those without bradycardia, patency was seen in $57 \%$ (27/47).

Table 2 shows the sensitivity, specificity, and the predictive value of the occurrence of various rhythm disturbances for patency.

Table 1 Characteristics and incidence of ventricular arrhythmias in 57 patients who were treated with intravenous streptokinase for acute myocardial infarction

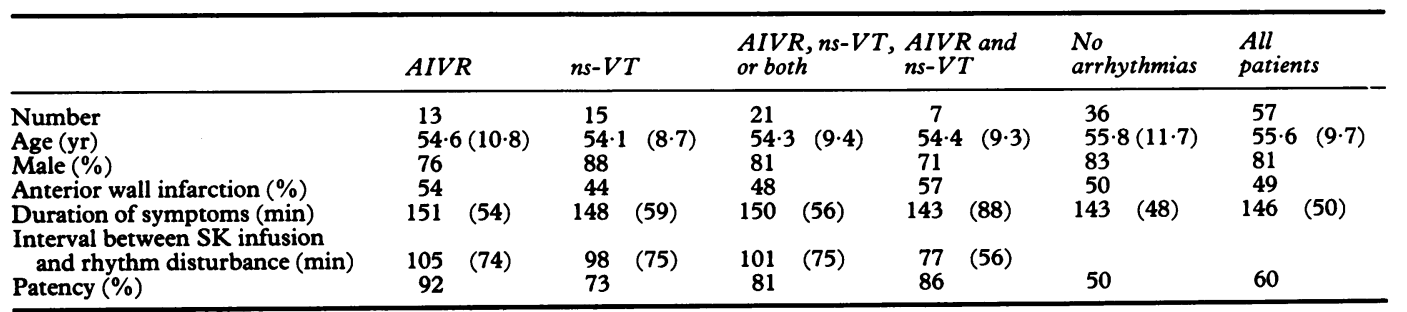

AIVR, accelerated idioventricular rhythm; ns-VT, non-sustained ventricular tachycardia; SK, streptokinase. 
Table 2 Sensitivity, specificity, and predictive values of the occurrence of various rhythm disturbances for patency of the infarct-related coronary artery of 57 patients, of whom 34 had a patent vessel (numbers in parentheses are $95 \%$ confidence intervals)

\begin{tabular}{|c|c|c|c|c|c|}
\hline Arrhythmia & $\begin{array}{l}\text { Number of } \\
\text { patients } \\
\text { with rhythm } \\
\text { disturbances }\end{array}$ & $\begin{array}{l}\text { Sensitivity } \\
(\%)\end{array}$ & $\begin{array}{l}\text { Specificity } \\
(\%)\end{array}$ & $\begin{array}{l}\text { Predictive } \\
\text { value of } \\
\text { positive test } \\
(\%)\end{array}$ & $\begin{array}{l}\text { Predictive } \\
\text { value of } \\
\text { negative test } \\
(\%)\end{array}$ \\
\hline AIVR & 13 & $\begin{array}{l}35 \\
(20 \text { to } 52)\end{array}$ & $\begin{array}{l}96 \\
\text { (78 to } 99)\end{array}$ & $\begin{array}{l}92 \\
\text { (66 to } 99)\end{array}$ & $\begin{array}{l}50 \\
\text { (34 to } 66)\end{array}$ \\
\hline Non-sustained VT & 15 & $\begin{array}{l}32 \\
(18 \text { to } 50)\end{array}$ & $\begin{array}{l}83 \\
\text { (62 to } 95)\end{array}$ & $\begin{array}{l}73 \\
\text { (45 to } 92)\end{array}$ & $\begin{array}{l}45 \\
\text { (29 to } 61)\end{array}$ \\
\hline AIVR or non-sustained VT or both & 21 & $\begin{array}{l}50 \\
\text { (32 to } 68)\end{array}$ & $\begin{array}{l}83 \\
(62 \text { to } 95)\end{array}$ & $\begin{array}{l}81 \\
(58 \text { to } 94)\end{array}$ & $\begin{array}{l}53 \\
\text { (35 to } 71 \text { ) }\end{array}$ \\
\hline AIVR and non-sustained VT & 7 & $\begin{array}{l}18 \\
(7 \text { to } 34)\end{array}$ & $\begin{array}{l}96 \\
\text { (78 to } 99)\end{array}$ & $\begin{array}{l}86 \\
(54 \text { to } 99)\end{array}$ & $\begin{array}{l}44 \\
\text { (30 to 59) }\end{array}$ \\
\hline Ventricular fibrillation & 2 & 6 (1 to 19$)$ & $\begin{array}{l}100 \\
(86 \text { to } 100)\end{array}$ & 100 & $\begin{array}{l}42 \\
(28 \text { to } 56)\end{array}$ \\
\hline Bradycardia & 10 & $\begin{array}{l}21 \\
(9 \text { to } 37)\end{array}$ & $\begin{array}{l}87 \\
\text { (67 to } 97)\end{array}$ & $\begin{array}{l}70 \\
\text { (35 to } 93 \text { ) }\end{array}$ & $\begin{array}{l}43 \\
\text { (28 to } 58)\end{array}$ \\
\hline
\end{tabular}

AIVR, accelerated idioventricular rhythm; VT, ventricular tachycardia.

\section{Discussion}

Necrosis and/or ischaemia of myocardial cells may initiate abnormal ventricular depolarisations which are currently thought to be triggered by reentry or triggered activity. ${ }^{11-15}$ Ventricular rhythm disturbances, however, may also be caused by reperfusion and in such cases reentry or enhanced automaticity may play a role. ${ }^{16}$

\section{REPERFUSION ARRHYTHMIAS IN ANIMALS}

An interesting aspect of reperfusion arrhythmias is the existence of an apparent species specificity. In some laboratory animals the occurrence of arrhythmias can be considered as a reliable non-invasive sign of reperfusion..$^{2-6}$ Ventricular tachycardias and fibrillation are often seen in dogs, ${ }^{46}$ pigs, and rats $^{3}$ immediately after reperfusion, though this is less common in cats. ${ }^{25}$

\section{REPERFUSION ARRHYTHMIAS IN HUMANS}

We obtained Holter recordings in a welldefined period of the acute infarction: from shortly before the start of thrombolytic therapy to the primary end point of the study (the injection of contrast agent into the infarctrelated coronary artery). We emphasise that our patients were generally not treated with antiarrhythmic drugs. It seemed that accelerated idioventricular rhythm gave the highest scores in predicting the outcome of angiography. Accelerated idioventricular rhythm predicted patency in $92 \%$ of patients; but on the other hand, its absence predicted a permanent occlusion in only $50 \%$. So this arrhythmia has a very high specificity $(96 \%)$ and a poor sensitivity (35\%) as a non-invasive index of patency. It should also be noted that coronary angiography is only a "snapshot"; it does not exclude intermittent occlusion and recanalisation. ${ }^{17}$ None the less, it is the best diagnostic tool for recording the coronary anatomy that is clinically available.

Sustained ventricular tachycardia or ventricular fibrillation did not occur during the period of investigation. However, before the period of investigation two patients with patent vessels had ventricular fibrillation, which suggests that there may be a relation between the occurrence of ventricular fibrillation and patency, but this sample size is too small to draw any conclusions.

Non-sustained ventricular tachycardia was slightly more common than accelerated idioventricular rhythm (15 patients $v 13$ patients, respectively), but non-sustained ventricular tachycardia has both a poorer specificity $(83 \%)$ and sensitivity $(32 \%)$ than does accelerated idioventricular rhythm.

\section{COMPARISON WITH OTHER STUDIES}

Large controlled trials showed that life threatening arrhythmias were less common in patients after thrombolytic therapy than in control groups. ${ }^{18-20}$ Furthermore, Theroux and coworkers showed that the number of ventricular extrasystoles per hour during the first 24 hours of infarction was significantly less after thrombolysis than after conservative treatment. $^{21}$

Arrhythmias during intracoronary streptokinase administration in humans have been described (specifically) in three studies, ${ }^{22-24}$ which, unfortunately, are difficult studies to compare for the following reasons. First, the definition of "reperfusion arrhythmias" differed from study to study. Secondly, in such a type of investigation, arrhythmias that were less relevant to the course of action in the coronary care unit (such as accelerated idioventricular rhythm) were often ignored. For instance, in our study, we found that the routine records of rhythm kept by the nursing staff were not complete: seven of the 13 episodes of accelerated idioventricular rhythm that were found on the Holter recordings were not recorded. This may partly explain why other studies did not show that rhythm disturbances in routine rhythm strip recordings were predictive for patency. ${ }^{1}$ Thirdly, the incidence of reperfusion arrhythmias may be different with intracoronary and intravenous streptokinase administration. Also, routine administration of antiarrhythmic drugs may influence the incidence of arrhythmias; indeed in the studies described by Goldberg et al and Miller et al patients were routinely treated with lignocaine. $^{22} 23$

\section{TIME OF REPERFUSION}

Animal studies showed that arrhythmias occur 
at the time of reperfusion. So rhythm recordings can be used to calculate the interval from the onset of symptoms until reperfusion. This is a non-invasive method of calculating the total period of tissue anoxia. Such information may be of great value when the effects of thrombolytic drugs administered at different rates of infusion are compared. It cannot be obtained by angiography or other non-invasive methods such as enzyme studies. ${ }^{25}$

\section{CLINICAL IMPLICATIONS}

In view of the results of the TIMI II study of the therapeutic strategy after thrombolytic therapy, does information on patency have any practical consequence? ${ }^{26}$ There were no clear benefits with either invasive or conservative management of patients after thrombolytic therapy, regardless of whether or not recanalisation was achieved. Nevertheless, the presence of accelerated idioventricular rhythm is highly predictive of patency and easy to record. This may make it a useful method for calculating the total anoxia period, so it seems sensible to instruct the nursing staff on the importance of this arrhythmia.

We thank Eleana Moyer for reviewing the manuscript and Valerie Arneson for statistical advice.

1 Califf RM, O'Neil W, Stack RS, et al. TAMI Study Group. Failure of simple clinical measurements to predict perFailure of simple clinical measurements to predict perMed 1988;108:658-62.

2 Zuanetti G, Vanoli E, Zaza A, Priori S, Stromba-Badiale M. Schwartz PJ. Lack of correlation between occlusion and reperfusion arrhythmias in the cat. Am Heart J 1985; 109:932-6.

3 van Gilst WH, de Graeff PA, Kingma JH, Wesseling H, de Langen CDJ. Captopril reduces purine loss and reperfusion arrhythmias in the rat heart after coronary artery occlusion. Eur J Pharmacol 1984;110:113-7.

4 Sheehan FH, Epstein SE. Effects of calcium channel blocking agents on reperfusion arrhythmias. Am Heart $J 1982$ 103:973-7.

5 Pogwizd SM, Corr PB. Electrophysiologic mechanisms underlying arrhythmias due to reperfusion of ischemic underlying arrhythmias due to reperfusion

6 Bolli R, Patel B. Factors that determine the occurrence of reperfusion arrhythmias. Am Heart J 1988;115:20-9.

7 Six AJ, Louwerenburg HW, Braams R, et al. A double-blind randomized multicenter dose-ranging trial of intravenous 1990;65:119-23.
8 Kingma JH, Louwerenburg JW, Six AJ, van Gilst WH, de Graeff PA, Wesseling H. Concomitant use of captopril during thrombolytic therapy in acute myocardial infarction. In: Sonnenblick EH, Laragh JH, Lesh M, eds. New frontiers in cardiovascular therapy: focus on angiotensin converting enzyme inhibition. Princeton: Excerpta Medica 1989:277-85

9 Sheehan FH, Braunwald E, Canner P, et al. The effect of intravenous thrombolytic therapy on left ventricular funcion: a report on tissue-type plasminogen activator and tion: a report on tissue-type plasminogen activator an streptokinase from the Thrombolysis in Myocardia 817-29.

10 Steel RGD, Torrie JH. Principles and procedures of statistics. New York: McGraw Hill, 1960 :table A14A on page 454

11 Janse MJ, Kleber AG. Electrophysiological changes and ventricular arrhythmias in the early phase of regional ventricular arrhythmias in the early phase of reg

12 Janse MJ, Capelle FJL, Morsink H, et al. Flow of "injury" current and patterns of excitation during early ventricula arrhythmias in acute regional myocardial ischaemia in isolated porcine and canine hearts. Evidence for two different arrhythmogenic mechanisms. Circ Res 1980 47:151-65.

13 van Hemel NM, Swenne CA, Robles de Medina EO. Assessment of mechanisms of ventricular arrhythmias from the surface electrocardiogram in 118 patients. Eur Heart $J 1987 ; 8: 813-20$.

14 Manning AS, Hearse DJ. Reperfusion-induced arrhythmias: mechanisms and prevention. J Mol Cell Cardiol 1984;16:497-518.

15 Hoffman B Rosen M. Cellular mechanisms for cardiac arrhythmias. Circ Res 1981;49:1-15.

16 Manning AS, Hearse DJ. Reperfusion-induced arrhythmias: mechanism and prevention. J Mol Cell Cardiol 1984, 16:497-518.

17 Hackett D, Davies G, Chierchia S, Maseri A. Intermitten coronary occlusion in acute myocardial infarction. $N$ Eng J Med 1987;317:1055-9.

18 GISSI. Effectiveness of intravenous thrombolytic treatmen in acute myocardial infarction. Lancet 1986;i:397-402.

19 ISAM study group. A prospective trial of intravenous streptokinase in acute myocardial infarction. $N$ Engl Med 1986;314:1465-71.

20 Simoons ML, Serruys PW, van den Brand $M$, et al. Improved survival after early thrombolysis in acute myocardial infarction. Lancet 1985;ii:578-81.

21 Theroux $P$ Morisette $D$, Juneau $M$, de Guise $P$, Pelletier $G$, Waters DD. Influence of fibrinolysis and percutaneous transluminal coronary angioplasty on the frequency of transluminal coronary angioplasty on the frequency of ventricular

22 Goldberg S, Greenspon AJ, Urban PL, et al. Reperfusion arrhythmia: a marker of restoration of antegrade flow during intracoronary thrombolysis for acute myocardia infarction. Am Heart $J$ 1983;105:26-32.

23 Miller FC, Krocoff MW, Satler LF, et al. Ventricula arrhythmias during reperfusion. Am Heart $J$ 1986;112: 928-32.

24 Kuck KH, Schofer J, Schlüter M, Bleifeld W, Mathey D. Reperfusion arrhythmias in man: influence of intravenou lidocaine. Eur Heart J 1985;6(suppl E):163-7.

25 Katus HA, Diederich KW, Scheffold T, Uellner M, Schwar $F$, Kübler W. Noninvasive assessment of infarct reperfusion: the predictive power of the time to peak value of myoglobin $C K M B$, and $C K$ in serum. Eur Heart $J$ 1988;9:619-24.

26 The TIMI Study Group. Comparison of invasive and conservative strategies after treatment with intravenous tissue plasminogen activator in acute myocardial infarction. N Engl J Med 1989;320:618-27. 